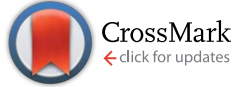

Cite this: RSC Adv., 2016, 6, 52772

Received 5th April 2016

Accepted 19th May 2016

DOI: $10.1039 / \mathrm{c} 6 \mathrm{ra0} 8724 \mathrm{~h}$

www.rsc.org/advances

\section{Guanidinium rich dendron-appended hydnocarpin exhibits superior anti-neoplastic effects through caspase mediated apoptosis $\uparrow$}

\begin{abstract}
Bincy Mariyam Mathai, ${ }^{a}$ Manu M. Joseph, ${ }^{a}$ Santhi Maniganda, ${ }^{\text {ab }}$ Jyothi B. Nair, ${ }^{\text {ab }}$ J. S. Arya, ${ }^{a}$ Varsha Karunakaran, ${ }^{\text {ab }}$ K. V. Radhakrishnan*ab and Kaustabh Kumar Maiti ${ }^{\star a b}$

Medicinal plants have truly demonstrated their potential as a repository of active biomolecules with promising therapeutic potential and represent an important source for the identification of novel drug leads. Hydnocarpus wightiana Blume is a well known medicinal plant and the acetone extract of its seed demonstrated superior free radical scavenging properties with a high total phenolic and flavonoid content. Hydnocarpin ( $\mathrm{Hy})$, which has been isolated and purified from the acetone extract, promotes moderate cytotoxicity in cancer cells. In an attempt to increase the efficiency of Hy as an anticancer agent, chemical coupling with a highly efficient, non-toxic cell-penetrating guanidinium-rich poly(propylene imine) dendron (G8) was attempted. The resultant modified construct ( $\mathrm{Hy}-\mathrm{G} 8$ ) exhibits superior cytotoxicity preferentially on cancer cells through the induction of apoptosis mediated by caspases. The hybrid construct was also found to be a promising anti-metastatic agent. Therefore, HyG8 functioned primarily as a hit compound which requires extensive interdisciplinary approaches and legitimate engineering to accomplish a futuristic lead candidate in cancer chemotherapy.
\end{abstract}

\section{Introduction}

A copious amount of natural resources ${ }^{1}$ for restorative uses exist around the world, of which numerous have not yet been successfully tapped for the development of conceivable drug candidates. Despite extensive research on compounds of natural origin to produce new drug substances occurring, research specifically aimed at naturally derived medicines to optimize dosages for the intended route of administration and to design the most effective dosage forms, has become a greater challenge. Many of the traditional medicines have real, beneficial effects and extracts of these crude combinations lead to the discovery of their active ingredients and eventually to the development of modern chemically pure drugs. In general, phytochemicals identified from traditional medicinal plants are presenting exhilarating opportunities for the development of new drug candidates. Several studies revealed that chemically modified natural compounds, especially from medicinal plants ${ }^{2}$ generated better responses as candidate lead molecules in the field of cancer therapy. Cancer ${ }^{3}$ continues to be one of the

${ }^{a}$ Chemical Sciences \& Technology Division (CSTD), Organic Chemistry Section, CSIR-National Institute for Interdisciplinary Science \& Technology (CSIR-NIIST), Industrial Estate, Pappanamcode, Thiruvananthapuram-695019, Kerala, India. E-mail:kkmaiti@niist.res.in; kkmaiti29@gmail.com

${ }^{b}$ Academy of Scientific and Innovative Research (AcSIR), New Delhi, India

† Electronic supplementary information (ESI) available. See DOI: 10.1039/c6ra08724h major causes of death worldwide with only modest progress being made in reducing the morbidity and mortality of the disease. Phytochemicals from extracts of roots, bulbs, barks, leaves, stems and others parts of plants have shown promising potential as anti-cancer drugs or for serving as lead compounds in the synthesis of new drugs. They are often utilized as traditional medicines in the form of homemade tinctures, teas or crude extracts, but are accompanied by drawbacks, including batch to batch variation in preparation methods and hence in their chemical composition.

Hydnocarpus wightiana Blume ${ }^{3-6}$ (Flacourtiaceae), is widely cultivated in Southeast Asia, mainly in China, Taiwan, Indonesia, Malaysia and Thailand. Four species occur in India, one of which grows up to 50 feet and is commonly known as Chaulmoogra with globose fruits containing 15-20 seeds. Chaulmoogra oil, extracted from the seeds, has traditionally been effectively used in the treatment of leprosy, chronic skin infections, ophthalmia, and for dressing wounds and ulcers. The plant has also been attributed with anti-obesity activity and the seed $^{3-7}$ oil is also used in traditional applications in rheumatism, sprains and bruises, sciatica and chest infections. The seeds possess high medicinal value because they are reported to contain an array of therapeutically significant classes of phytochemicals such as triterpenoids, flavones, aglycones, glycosides and a range of fatty acids and esters. Seed extracts yield compounds structurally related to the flavonolignans $s^{6,8}$ namely hydnowightin, hydnocarpin, neohydnocarpin, isohydnocarpin and luteolin. Even though all five flavonolignans 
demonstrated antidiabetic and antioxidant activities, and moderate cytotoxicity against few cancer cell lines, ${ }^{9,10}$ hydnocarpin proved to be the most promising agent ${ }^{4,11}$ with significant cytotoxicity against cancer cells of various origins.

Given their phenomenal concoction of assorted qualities and novel modes of action, natural products keep on working as lead compounds in many drug discovery programs. However, to keep up with the ongoing demand for new therapeutic agents, new strategies for enhancing their therapeutic potential are needed. Semi-synthetic modifications of natural products aimed at enhancing their biological properties or the total synthesis of analogues serve as great starting points for generating molecules with greater bio-availability, bio-distribution and rapid bio-response. Molecular transporters containing octaguanidine residues enhanced the cell penetrating ability most effectively and delivered a variety of cargos. ${ }^{12}$ To date our group has developed a new guanidinium rich poly(propylene imine) dendron based molecular transporter, ${ }^{13}$ which was observed to be non-toxic with higher cellular uptake efficiency compared with Arg-8-mer in various cancer cells. The high cell penetrating ability of the G8-dendron encourages us to develop a new hydnocarpin-appended guanidium-rich dendron ( $\mathrm{Hy}-$ G8). The new synthetic derivative demonstrated excellent water solubility and improved cytotoxicity via caspase-mediated apoptosis in cancer cells. The systematic approach adopted in the current study is illustrated in Fig. 1.

\section{Experimental}

\subsection{Materials and methods}

IR spectra were recorded on a Bruker Alpha FT-IR spectrometer. ${ }^{1} \mathrm{H}$ NMR spectra were recorded at $500 \mathrm{MHz}$ using deuterated methanol $\left(\mathrm{CD}_{3} \mathrm{OD}\right)$ as the solvent on a Bruker $\mathrm{AV} 500$

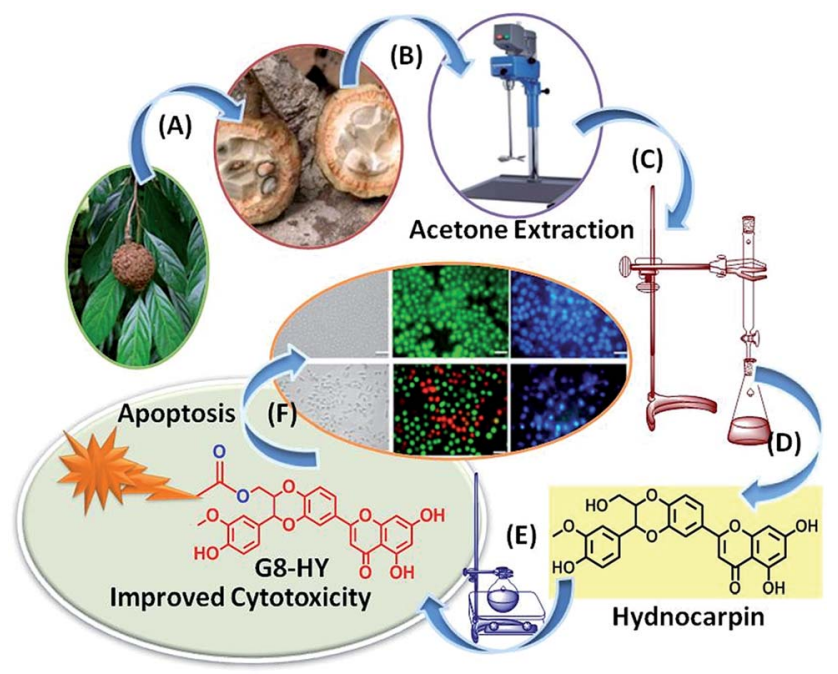

Fig. 1 Thematic representation of $\mathrm{Hy}-\mathrm{G} 8$ derivative synthesis. (A) Separation of seeds from Hydnocarpus wightiana Blume, (B) acetone extraction of the seeds, (C) column chromatographic separation, (D) isolation and purification of hydnocarpin, (E) synthetic transformation with G8-PPI dendrons and (F) biological evaluation of Hy-G8. spectrometer. Tetramethylsilane (TMS) was used as the internal standard and chemical shift values are expressed in $\delta$-scale in units of parts per million (ppm) and coupling constants $(J)$ in Hz. Mass spectra were recorded using a Thermo Scientific Exactive mass spectrometer under ESI/HRMS at 61800 resolution. Analytical thin layer chromatography was performed on a Merck $60 \mathrm{~F}_{254}$ silica gel plate $(0.25 \mathrm{~mm}$ thickness) and visualization was done with UV light $(254 \mathrm{~nm}$ and $365 \mathrm{~nm})$ and column chromatography using Merck silica gel (100-200 mesh). Chromatography was carried out using varying polarities of hexane-ethyl acetate mixtures as solvent. Other chemicals were purchased from Sigma Aldrich and Merck.

\subsection{Preparation of extracts}

The seeds of Hydnocarpus wightiana Blume were thoroughly cleaned and dried in air in an oven maintained at $40{ }^{\circ} \mathrm{C}$ for three days. They were then thoroughly powdered and weighed approximately $750 \mathrm{~g}$. The powdered material was first extracted using hexane in a mechanical stirrer $(1.5 \mathrm{~L})$ three times at room temperature. It was further extracted using chloroform $(1.5 \mathrm{~L})$ three times and finally with acetone $(1.5 \mathrm{~L})$ three times at room temperature. The total extracts were concentrated under reduced pressure using a Buchii rotary evaporator. This yielded about $400 \mathrm{~g}$ of the crude hexane extract, $25 \mathrm{~g}$ of chloroform and $45 \mathrm{~g}$ of acetone extract. Based on observation in TLC, the acetone extract was selected for the isolation of compounds.

\subsection{Antioxidant activity}

Earlier studies revealed that the hexane and chloroform extracts of Hydnocarpus wightiana Blume do not have any appreciable free radical scavenging activity and the acetone extract possesses antioxidant activity against selected free radicals. ${ }^{\mathbf{1 4}}$ This encouraged us to examine the free radical scavenging properties of the acetone extract against experimentally generated free radicals by established antioxidant assays.

2.3.1. DPPH radical scavenging assay. The radical scavenging effects of the acetone extract on a 1,1-diphenyl-2-picrylhydrazil (DPPH) radical were estimated..$^{15}$ Various concentrations of samples and standards $(3 \mathrm{~mL})$ were mixed with $1 \mathrm{~mL}$ of $0.1 \mathrm{mM}$ DPPH and the mixture was shaken vigorously and allowed to incubate at room temperature $\left(25 \pm 3{ }^{\circ} \mathrm{C}\right)$ for $30 \mathrm{~min}$. The scavenging activity was quantified spectrophotometrically at $507 \mathrm{~nm}$ against $95 \%$ ethanol as blank. Ascorbic acid was used as the standard and the percent DPPH scavenging effect was expressed as percent inhibition from the given formula:

$$
\% \text { inhibition of DPPH radical }=\left[A_{0}-A_{1} / A_{0}\right] \times 100
$$

where $A_{0}$ was the absorbance of the control and $A_{1}$ was the absorbance of the sample/standard.

2.3.2. FRAP (ferric reducing antioxidant power) assay. This assay measures the total antioxidant capacity of the compound and the procedure was conducted according to Benzie and Strain ${ }^{16}$ with modification. The working FRAP reagent was prepared by mixing $300 \mathrm{mM}$ acetate buffer (pH 3.6), $10 \mathrm{mM}$ 2,4,6-tripytidyl-s-triazine (TPTZ) solution and $20 \mathrm{mM}$ 
$\mathrm{FeCl}_{3} \cdot 6 \mathrm{H}_{2} \mathrm{O}$ in a $10: 1: 1$ ratio prior to use and heated to $37^{\circ} \mathrm{C}$ in a water bath. Three millilitres $(3 \mathrm{~mL})$ of FRAP reagent was added to $100 \mu \mathrm{L}$ of various concentrations of the samples and standards. Absorbance was measured at $593 \mathrm{~nm}$ at $0 \mathrm{~min}$ and again after $90 \mathrm{~min}$. Ascorbic acid was used as the standard and changes in the absorbance after $90 \mathrm{~min}$ from the initial reading were compared and percent inhibition was calculated as described.

2.3.3. Hydroxyl radical scavenging assay. Hydroxyl radical scavenging activity was measured by comparing deoxyribose and the acetone extract for hydroxyl radicals generated by the $\mathrm{Fe}^{3+}$-ascorbate-EDTA- $\mathrm{H}_{2} \mathrm{O}_{2}$ system (Fenton reaction). ${ }^{17}$ The reaction mixture $(1 \mathrm{~mL})$, containing $100 \mu \mathrm{L}$ 2-deoxy-2-ribose (28 $\mathrm{mM}$ in $20 \mathrm{mM}$ phosphate buffer, $\mathrm{pH} 7.4), 500 \mu \mathrm{L}$ of different concentrations of the samples and controls, $200 \mu \mathrm{L} 1.04 \mathrm{mM}$ $\mathrm{FeCl}_{3}, 100 \mu \mathrm{L} 1 \mathrm{mM} \mathrm{H}_{2} \mathrm{O}_{2}$ and $100 \mu \mathrm{L}$ ascorbic acid, was incubated at $37{ }^{\circ} \mathrm{C}$ for $1 \mathrm{~h}$. Thiobarbituric acid (1\%) and trichloroacetic acid $(2.8 \%)$ were added and incubated at $100{ }^{\circ} \mathrm{C}$ for 20 min and after rapid cooling the absorbance was measured at $532 \mathrm{~nm}$. Alpha tocopherol was used as the standard and the percent inhibition was calculated.

2.3.4. Superoxide radical scavenging assay. The scavenging activity towards superoxide anion radicals was measured by the method of Liu et al. ${ }^{18}$ Superoxide anions were generated in a non-enzymatic phenazine methosulfate nicotinamide adenine dinucleotide (PMS-NADH) system through the reaction of PMS, NADH and oxygen. It was assayed by the reduction of nitroblue tetrazolium (NBT). Superoxide anions were generated in $3 \mathrm{~mL}$ of Tris- $\mathrm{HCl}$ buffer $(100 \mathrm{mM}$, pH 7.4) containing $0.75 \mathrm{~mL}$ of NBT $(300 \mu \mathrm{M})$ solution, $0.75 \mathrm{~mL}$ of $\mathrm{NADH}(936 \mu \mathrm{M})$ solution and $0.3 \mathrm{~mL}$ of various concentrations of samples and standards. The reaction was initiated by adding $0.75 \mathrm{~mL}$ of PMS $(120 \mu \mathrm{M})$ to the mixture. After $5 \mathrm{~min}$ of incubation at room temperature (25 $\pm 3{ }^{\circ} \mathrm{C}$ ), the absorbance at $560 \mathrm{~nm}$ was measured. Alpha tocopherol was used as the positive control and percent inhibition was calculated.

\subsection{Total phenolic content (TPC)}

Total phenolic content ${ }^{\mathbf{1 9 2 0}}$ (TPC) of the acetone extract was determined using the Folin-Ciocalteu reagent. Briefly, $0.5 \mathrm{~mL}$ of freshly prepared Folin-Ciocalteu reagent in distilled water $(1: 2)$, was added to $1.0 \mathrm{~mL}$ extracts of different concentrations (200-1000 $\mu \mathrm{g} \mathrm{mL}^{-1}$ ) and mixed thoroughly and then neutralized with $1 \mathrm{~mL}$ saturated sodium carbonate solution and made up to $10 \mathrm{~mL}$ with distilled water. After $2 \mathrm{~h}$, the absorbance of the resulting solution was measured at $764 \mathrm{~nm}$ using a spectrophotometer. The TPC was determined by plotting the gallic acid calibration curve (20 to100 $\mu \mathrm{g} \mathrm{mL}^{-1}$ ) and expressed as gallic acid equivalents (mg GAE/100 $\mathrm{g}$ dry weight of sample).

\subsection{Total flavonoid content (TFC)}

About $1 \mathrm{~mL}$ of acetone extract $\left(1 \mathrm{mg} \mathrm{mL}{ }^{-1}\right)$ was made up to $5 \mathrm{~mL}$ using distilled water and $0.3 \mathrm{~mL}$ of $5 \%(\mathrm{w} / \mathrm{v}) \mathrm{NaNO}_{2}$ was added to it and kept for $5 \mathrm{~min}$. After $5 \mathrm{~min}$. $0.3 \mathrm{~mL}$ of $10 \%(\mathrm{w} / \mathrm{v}) \mathrm{AlCl}_{3}$ was added to form a flavonoid-aluminum complex. After $6 \mathrm{~min}$, $2 \mathrm{~mL}$ of $1 \mathrm{M} \mathrm{NaOH}$ was added and the total volume was made up to $10 \mathrm{~mL}$ using distilled water. The solution was mixed well again and the absorbance was measured against a reagent blank, at $415 \mathrm{~nm}$. The blank was prepared by adding all reagents except $\mathrm{AlCl}_{3}$. Distilled water was added in place of $\mathrm{AlCl}_{3}$ in the blank. The TFC was determined by plotting the quercetin calibration curve (20 to100 $\mu \mathrm{g} \mathrm{mL}^{-1}$ ) and expressed as milligrams of quercetin equivalents $(\mathrm{mg} \mathrm{QE} / 100 \mathrm{~g}$ of dry weight of sample). ${ }^{21}$

\subsection{Isolation of compounds and its chemical modification}

Based on the observation in TLC, the acetone extract was used for the isolation of compounds. A fatty acid rich fraction was isolated from the hexane extract. The acetone extract, which showed good anti-oxidant activity, total phenolic and good flavonoid content, was selected for further in depth studies. It was subjected to column chromatography using silica gel (100200 mesh), the column was eluted with chloroform and an increasing amount of methanol which yielded 574 different fractions. From 354-407 fractions, we have isolated our target compound hydnocarpin in good yield.

2.6.1. Hydnocarpin (Hy). IR (KBr, $\nu_{\max }, \mathrm{cm}^{-1}$ ): 3186, 2961, $1664,1625,1518,1437,1383,1271,1164,895,800 ;{ }^{1} \mathrm{H}$ NMR $(500$ $\left.\mathrm{MHz}, \mathrm{CD}_{3} \mathrm{OD}\right): \delta 8.65(\mathrm{~s}, 1 \mathrm{H}), 7.55(\mathrm{~d}, J=8.2,1 \mathrm{H}), 7.09(\mathrm{~d}, J=$ $8.7,1 \mathrm{H}), 7.05,(\mathrm{~s}, 1 \mathrm{H}), 6.94(\mathrm{~d}, J=8.7,1 \mathrm{H}), 6.88(\mathrm{~d}, J=8.0,1 \mathrm{H})$, $6.66(\mathrm{~s}, 1 \mathrm{H}), 6.49(\mathrm{~s}, 1 \mathrm{H}), 6.25(\mathrm{~s}, 1 \mathrm{H}), 4.18-4.16(\mathrm{~m}, 1 \mathrm{H}), 3.90(\mathrm{~s}$, $3 \mathrm{H}), 3.76(\mathrm{~d}, J=10.8,1 \mathrm{H}), 3.54\left(\mathrm{dd}, J_{1}=12.1, J_{2}=3.95,1 \mathrm{H}\right), 3.46$ (s, 1H) (ESI Fig. $1 \dagger) ;{ }^{13} \mathrm{C}$ NMR (125 MHz, $\left.\mathrm{CD}_{3} \mathrm{OD}\right): \delta 181.7,164.2$, 162.8 , 161.3, 157.3, 147.6, 147.1, 147.0, 143.6, 126.9, 123.6, $120.5,119.8,117.5,115.3,114.7,111.6,103.8,103.7,98.9,94.0$, 77.9, 76.3, 60.0, 55.6; HR-MS ( $m / z): 465.1183$ ( $\mathrm{M}+1$ peak).

2.6.2. Hypnocarpin guanidinium derivative (Hy-G8). To the solution of hydnocarpin (15 $\mathrm{mg}, 0.3232 \mathrm{mmol}$ ) in dry DMF (3 mL), Boc-protected G8-PPI (92 mg, $0.03232 \mathrm{mmol}$ ), prepared using a previously reported procedure from our group (ESI Section $2 \dagger),{ }^{13}$ a catalytic amount of DMAP (base) and 1-ethyl-3(3-dimethylaminopropyl)carbodiimide (EDC) $(7.33 \mathrm{mg}$, $0.03879 \mathrm{mmol}$ ) were added. The mixture was stirred at room temperature for $24 \mathrm{~h}$. Completion of the reaction was monitored through TLC and the volatile components were removed under rotary evaporation and the Boc-protected product Hy-Boc-G8 formed was purified by column chromatography. Ethyl acetate $(4 \mathrm{~mL})$ saturated with gaseous $\mathrm{HCl}$ was added to a solution of Hy-Boc-G8 in ethyl acetate $(1 \mathrm{~mL})$. The reaction mixture was stirred for $4 \mathrm{~h}$ then the solution was concentrated and the residue was washed with ethyl acetate to remove less polar impurities. The residue was dried and purified using MPLC on Supelclean $^{\text {TM }}$ LC-18 reverse-phase silica gel $\left(\mathrm{MeOH} / \mathrm{H}_{2} \mathrm{O}\right)$. The purity of the product was checked by HPLC (ESI Fig. $3 \dagger$ ) and then dissolved in de-ionised water yielding Hy-G8. The compound was identified by spectroscopic techniques (ESI Fig. $2 \dagger)$. IR (KBr, $\nu_{\text {max }}, \mathrm{cm}^{-1}$ ): 3473, 2922, 2817, 2579, 2377, 1747, 1642, 1501, 1260, 1180, 1164; ${ }^{1} \mathrm{H}$ NMR (500 MHz, $\left.\mathrm{CD}_{3} \mathrm{OD}\right)$ : $\delta$ 1.19-1.55 (m, 22H), $2.49(\mathrm{~m}, 20 \mathrm{H}), 2.52(\mathrm{~m}, 16 \mathrm{H}), 3.08(\mathrm{~m}$, $16 \mathrm{H}), 3.36(\mathrm{~m}, 8 \mathrm{H}), 3.52(\mathrm{~m}, 2 \mathrm{H}), 3.56(\mathrm{~m}, 6 \mathrm{H}), 3.68(\mathrm{~m}, 4 \mathrm{H}) .3 .74$ $(\mathrm{s}, 3 \mathrm{H}), 4.20(\mathrm{~d}, J=5 \mathrm{~Hz}, 2 \mathrm{H}), 4.26(\mathrm{~m}, 1 \mathrm{H}), 5.25(\mathrm{~d}, J=10 \mathrm{~Hz}$, 
1H), 6.29-7.57 (m, 9H). MALDI TOF MS calculated 1720.2400 and found 1721.3258 .

\subsection{Cell lines}

The human cancer cell line A549 (lung adenocarcinoma) was obtained from American Type Culture Collection (ATCC, USA). A375 (malignant melanoma) cells were obtained from NCCS, Pune, India. Fibroblast-like mouse preadipocyte cell line 3T3L1 was obtained from the Inter University Centre for Genomics and Gene Technology, University of Kerala, Thiruvananthapuram, India. The cells were maintained in DMEM media with $10 \%$ fetal bovine serum and $5 \% \mathrm{CO}_{2}$ with incubation at $37^{\circ} \mathrm{C}$.

\subsection{In vitro cytotoxicity assays}

The growth inhibition capacity of hydnocarpin (Hy) and hydnocarpin-G8 (Hy-G8) was evaluated in cancer cell lines using the 3-[4,5-dimethylthiazol-2-yl]-2,5-diphenyltetrazolium (MTT) assay as previously reported. ${ }^{22}$ This assay measures cell viability by assessing the cleavage of the tetrazolium salt by mitochondrial dehydrogenase. The absorbance was measured at $570 \mathrm{~nm}$ using a microplate spectrophotometer (BioTek Power Wave XS). The inhibitory rates on the cells were calculated using the following formulas:

$$
\begin{gathered}
\text { Proliferation rate }(\mathrm{PR}) \%=[\text { Abs sample/Abs control }] \times 100 ; \\
\text { Inhibitory rate }(\mathrm{IR}) \%=100-\mathrm{PR} .
\end{gathered}
$$

MTT assays were performed on A375, A549 and 3T3-L1 with various concentrations of $\mathrm{Hy}$ and $\mathrm{Hy}-\mathrm{G} 8$ ranging from $2.5 \mu \mathrm{g}$ $\mathrm{mL}^{-1}$ to $80 \mu \mathrm{M}$ for 24 and $48 \mathrm{~h}$.

The cytotoxicity of Hy-G8 was further confirmed by LDH assay (Pierce LDH Cytotoxicity Assay Kit-88953, USA) as per the protocol given in the kit using the respective controls. Finally the absorbance at $490 \mathrm{~nm}$ and $680 \mathrm{~nm}$ was measured using a plate-reading spectrophotometer to determine $\mathrm{LDH}$ activity.
1X51). Acridine orange-ethidium bromide dual staining is the most commonly used method to detect apoptosis and is based on the differential uptake of two fluorescent DNA binding dyes by viable and nonviable cells. Assessment of apoptosis using the acridine orange-ethidium bromide dual staining procedure was performed as described earlier. ${ }^{23}$ The cells were observed under an inverted fluorescent microscope, using a FITC filter (Olympus 1X51, Singapore) to view the apoptotic or nonapoptotic cells. Furthermore, TUNEL assay (Dead End ${ }^{\mathrm{TM}}$ fluorometric TUNEL system G3250, Promega, USA) was used to detect the incorporation of the fluorescein-12-dUTP in the fragmented DNA of apoptotic cells, using the terminal deoxynucleotidyl transferase recombinant (rTdT) enzyme as per the manufacturer's instruction using propidium iodide as counter stain.

\subsection{Caspase assay}

The effect of both initiator caspases (caspases 8, 9 and 2) and executioner caspases (caspase 3) was determined using Apo Alert $^{\mathrm{TM}}$ Caspase Profiling kit (Clontech, CA, USA) as per the kit protocol. Cells were treated with $20 \mu \mathrm{M}$ Hy-G8 for $24 \mathrm{~h}$ and finally, samples were transferred to 96-well plates for fluorometric reading (excitation: $380 \mathrm{~nm}$; emission: $460 \mathrm{~nm}$ ), and the OD obtained was recorded under a spectrofluorometer (FLx800, BioTek).

\subsection{Wound healing assay}

The scratch wound healing assay was performed to evaluate the anti-metastatic potential of Hy-G8 on A375 and A549 cells, as described previously. ${ }^{\mathbf{2 4 2 5}}$ The cancer cells have inherent potential for invasion and metastasis which makes them escape from the cytotoxic agent and establishes a tumor at a new niche. Hence evaluation of the anti-metastasis potential of any cytotoxic agent holds special attention. Briefly, cells were seeded into six-well plates at a density of $1.0 \times 10^{5}$ per well until they reached $80 \%$ confluence. A scrape was made through the confluent monolayer with a sterile plastic pipette tip of $1 \mathrm{~mm}$ diameter. Afterwards, the dishes were washed twice with PBS and incubated at $37^{\circ} \mathrm{C}$ in fresh DMEM complemented with $10 \%$

$$
\% \text { cytotoxicity }=\frac{\text { compound treated LDH activity }- \text { spontaneous LDH activity } \times 100}{\text { maximum LDH activity }- \text { spontaneous LDH activity }}
$$

\subsection{Apoptotic assays}

Evaluation of the mode of cytotoxicity exhibited by Hy-G8 was performed on cancer cells with various apoptotic assays after administration of Hy-G8 $(20 \mu \mathrm{M})$ for $24 \mathrm{~h}$. Morphological evaluation for apoptotic changes were performed under phase contrast microscope (Olympus 1X51, Singapore) under suitable magnification. Observation of nuclei for any changes was done with Hoechst staining and the cells were observed under an inverted fluorescent microscope using a DAPI filter (Olympus fetal bovine serum in the presence or absence of the indicated concentrations of Hy-G8. At the bottom side of each dish, three arbitrary places were marked where the width of the wound was measured with an inverted microscope (objective $\times 10$ ). The wells were rinsed with PBS three times to remove floating cells and debris. The culture plates were incubated at $37{ }^{\circ} \mathrm{C}$ and in $5 \% \mathrm{CO}_{2}$. Wound closure was expressed as the average \pm SEM of the difference between the measurements at time zero and the 12-24 h time period considered. 


\section{Results and discussion}

\subsection{Isolation of crude extracts from Hydnocarpus wightiana Blume seeds}

The seeds were subjected to extraction using hexane and acetone. The acetone extract was selected to screen for antioxidant activity and further fractionalization.

Thin layer chromatography of the acetone extract was carried out using solvents of polarity starting from $100 \%$ chloroform to $10 \%$ methanol in chloroform. After TLC analysis the extract was subjected to column chromatography. From the acetone extracts 574 fraction pools were collected and a further sub column of 374-407 yielded the isolation of hydnocarpin in good yield (Fig. 2).

\subsection{Antioxidant action of the acetone extract}

Screening of the acetone extract against a wide array of experimentally generated free radicals revealed the astonishing antioxidant properties $^{\mathbf{2 6}}$ of the extract. The DPPH radical was considered to be a model of lipophilic radicals; a chain reaction in lipophilic radicals was initiated by lipid autoxidation. ${ }^{27}$ The radical scavenging activity of the acetone extract against experimentally generated DPPH ions is shown in Fig. 3A, which showed excellent scavenging activity even at low concentrations. The scavenging activity increases in a concentration-dependent manner. The $\mathrm{IC}_{50}$ value of the acetone extract was found to be $262.7 \pm 1.3 \mu \mathrm{g} \mathrm{mL}^{-1}$ and for ascorbic acid it was $77.5 \pm 1.5 \mu \mathrm{g}$ $\mathrm{mL}^{-1}$. The FRAP assay directly measures total antioxidants or reductants in a sample. The antioxidant capacity of the acetone extract based on the ability to reduce ferric ions was calculated as percent of inhibition as shown in Fig. 3B. There is a gradual increase in antioxidant activity with an increase in concentration up to $500 \mu \mathrm{g} \mathrm{mL} \mathrm{mith}^{-1}$ an $\mathrm{IC}_{50}$ of $70 \pm 1.8 \mu \mathrm{g} \mathrm{mL} \mathrm{m}^{-1}$, whereas the standard ascorbic acid showed relatively stable activity even from lower concentrations with an $\mathrm{IC}_{50}$ less than even $1 \mu \mathrm{g} \mathrm{mL}^{-1}$. Hydroxyl radicals attack proteins, DNA, polyunsaturated fatty acids in membranes and most biological

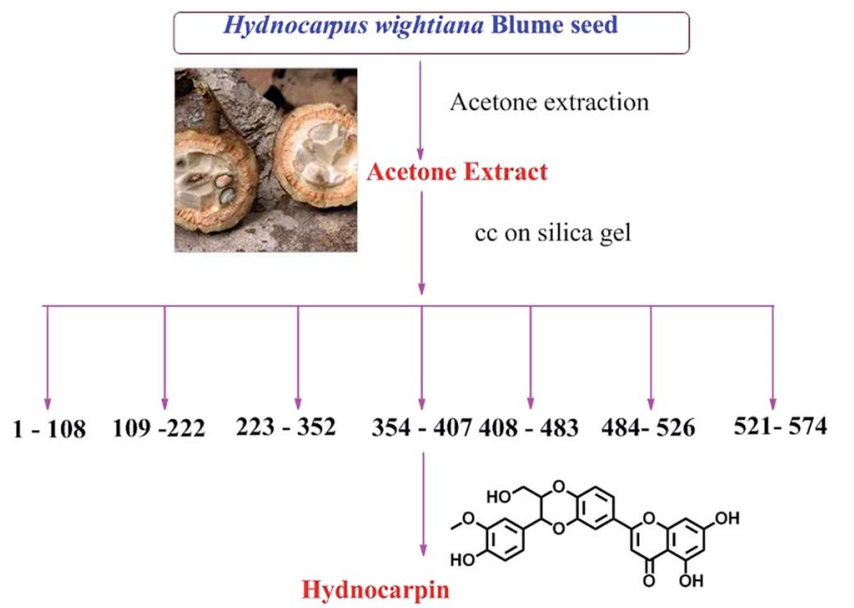

Fig. 2 Isolation of compounds from acetone extracts of Hydnocarpus wightiana Blume seeds.
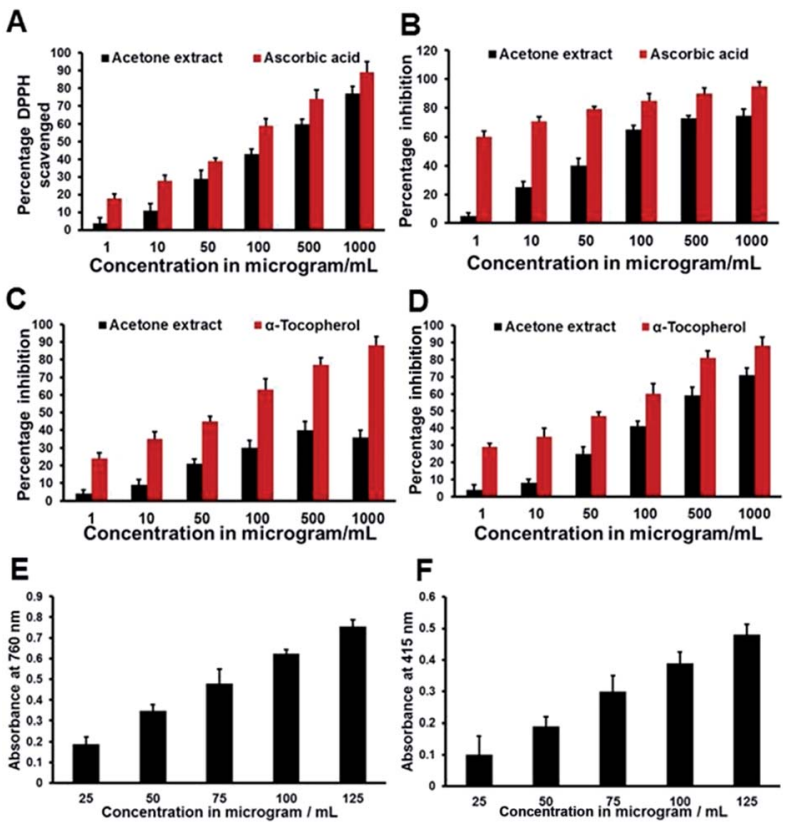

Fig. 3 The antioxidant activity of the acetone extract. (A) DPPH radical scavenging assay using ascorbic acid as the standard, (B) FRAP assay using ascorbic acid as the standard, (C) hydroxyl radical scavenging assay using alpha tocopherol as the standard and (D) superoxide radical scavenging assay using alpha tocopherol as the standard. (E) Total phenolic content (absorbance value of gallic acid at $760 \mathrm{~nm}$, expressed as gallic acid equivalent in $\mathrm{mg} \mathrm{g}^{-1}$ dry weight of sample) and (F) total flavonoid content (absorbance value of quercetin at $415 \mathrm{~nm}$ ), expressed as quercetin equivalent in $\mathrm{mg} \mathrm{g}^{-1}$ dry weight of sample.

molecules they contact, and are known to be capable of abstracting hydrogen atoms from membrane lipids and bring about peroxidation reactions with lipids. The acetone extract was not found to be a good scavenger of hydroxyl radical, with a maximum inhibition of $40 \%$ at $500 \mu \mathrm{g} \mathrm{mL} \mathrm{m}^{-1}$, whereas alpha tocopherol showed a good scavenging effect with an $\mathrm{IC}_{50}$ at $64 \mu \mathrm{g}$ $\mathrm{mL}^{-1}$ (Fig. 3C). The scavenging ability of the acetone extract against superoxide ions generated in the PMS-NADH-NBT system was shown in Fig. 3D. The acetone extract exhibited a dosedependent increase in scavenging activity with an $\mathrm{IC}_{50}$ at $299 \pm$ $2.8 \mu \mathrm{g} \mathrm{mL}^{-1}$ whereas the positive control alpha tocopherol gave an $\mathrm{IC}_{50}$ of $61.5 \pm 1.7 \mu \mathrm{g} \mathrm{mL} \mathrm{m}^{-1}$. The radical scavenging activity of the acetone extract is promising and might be helpful in preventing or reducing the progress of various oxidative stress-induced diseases including cancer and thereby be beneficial for human health. From the earlier studies it was proved that the compounds isolated from the acetone extract, hydnocarpin and isohydnocarpin, did not exhibit much antioxidant activity on a DPPH test model; the strong radical scavenging activity of the acetone extract might be due to the presence of luteolin in substantial amounts. Hence the use of the whole extract is preferable to its isolated compounds for free radical scavenging assays. ${ }^{14}$

\subsection{Total phenolic and flavonoid content}

The estimation of total phenolic content revealed that the acetone extract contains $642 \pm 27 \mathrm{mg}$ gallic acid equivalents in 
$100 \mathrm{~g}$ of extract. Total flavonoid content was determined by plotting the quercetin calibration curve $\left(20\right.$ to $\left.100 \mu \mathrm{g} \mathrm{mL}{ }^{-1}\right)$ and is expressed as milligrams of quercetin equivalents $(\mathrm{mg} \mathrm{QE} / 100$ grams of dry weight of sample). The study revealed that the acetone extract of Hydnocarpus wightiana Blume seeds contains $135 \pm 9 \mathrm{mg}$ quercetin equivalents in $100 \mathrm{~g}$ acetone extract. The concentration and type of phenolic substances are mainly responsible for the biological activities of the extract and high phenolic contents often attributes to higher free radical scavenging properties. ${ }^{28}$ Flavonoids are stable and effective scavengers of most oxidizing molecules, including singlet oxygen and various free radicals ${ }^{29}$ implicated in several diseases. The higher phenolic and flavonoid contents of the acetone extract could be highly responsible for the observed superior free radical scavenging effects.

\subsection{Synthetic modification of hydnocarpin}

The flavonolignan hydnocarpin ( $\mathrm{Hy}$ ) was isolated from acetone extract. Its structure is mostly similar to silybin and it can be characterized as a small, highly functionalized molecule with alternating carbo- and hetero-cycles. Preliminary screening for the cytotoxicity of Hy revealed moderate effects on cancer cells. The cytotoxic nature of Hy prompted us to investigate further structural modification in order to improve its bio-availability, water solubility and to consider transformed Hy as an excellent anti-cancer agent. Our group developed an excellent cell penetrating carrier with an octaguanidinium scaffold which shows higher cellular uptake compared to Arg-8-mer, the wellknown cell penetrating peptide. It has excellent selectivity towards the lysosome and the transporter alone (G8-PPI-FL) is found to be non-toxic. ${ }^{13}$ The primary alcoholic group at the C-23 position of $\mathrm{Hy}$ can be readily esterified and oxidized to a carboxylic acid. So, we have conjugated the primary $\mathrm{OH}$ of $\mathrm{Hy}$ with the acid terminal of the molecular transporter octaguanidinium-poly(propylene imine) hybrid dendron (G8-Boc-PPI) by ester coupling using carboxyl activating agent EDC in combination with DMAP (Scheme 1). Finally, all the Boc groups of the guanidine moieties were deprotected by treatment with ethyl acetate saturated with $\mathrm{HCl}$ gas reagent. The final compound

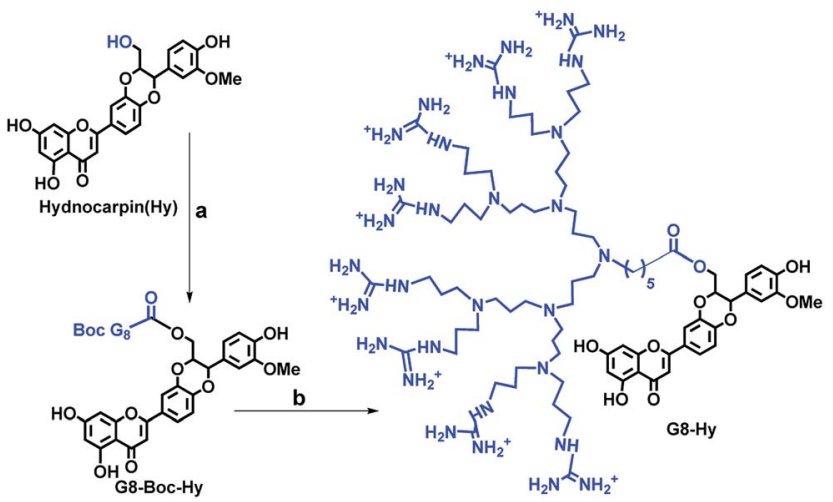

Scheme 1 Synthesis of hydnocarpin-G8 derivative; (a) EDC, DMAP, dry DMF, $\mathrm{N}_{2}$ atm, $36 \mathrm{~h}$; (b) EtOAc saturated with gaseous $\mathrm{HCl}$, EtOAc.
Hy-G8 was characterized by HPLC, NMR spectroscopy and MALDI-TOF mass spectrometry.

\subsection{Evaluation of cytotoxic potential}

Evaluation of cytotoxicity is the major step for any lead compounds aimed at human therapeutic applications. The cytotoxic potential was evaluated for $\mathrm{Hy}, \mathrm{Hy}-\mathrm{G} 8$ and the carrier G8 on A375, A549 and 3T3-L1 for 24 and $48 \mathrm{~h}$ from a wide dosage range of 2.5 to $80 \mu \mathrm{M}$ by MTT assay. Hy-G8 executed superior cytotoxicity than $\mathrm{Hy}$ in all dosages and incubation times towards A375 cells. Hy also executed significant cytotoxicity whereas the carrier G8 was found to be non-toxic (Fig. 4A, ESI Fig. 4A and $\mathrm{B} \dagger$ ). A375 cells were affected by Hy-G8 with an $\mathrm{IC}_{50}$ value of $22.7 \pm 0.9$ and $14.4 \pm 0.7$ at 24 and $48 \mathrm{~h}$, respectively, but $\mathrm{Hy}$ gave an $\mathrm{IC}_{50}$ at relatively higher concentrations of $57.6 \pm 1.3$ and $41.5 \pm 1.7$ at 24 and 48 h, respectively. A similar trend in cytotoxicity was observed for A549 cells, where Hy produced an $\mathrm{IC}_{50}$ of $72.7 \pm 1.4$ at $48 \mathrm{~h}$ but failed to generate an $\mathrm{IC}_{50}$ at $24 \mathrm{~h}$. A marked increase in cytotoxic potential was shown by Hy-G8 (Fig. 4B, ESI Fig. 4C and $\mathrm{D} \dagger$ ) with $\mathrm{IC}_{50} \mathrm{~s}$ of $33.7 \pm 0.9$ and $24 \pm 1.2$ at 24 and $48 \mathrm{~h}$, respectively. The cytotoxic potential of $\mathrm{Hy}$ and $\mathrm{Hy}-\mathrm{G} 8$ increased in a dose-dependent manner in both of the cancer cell lines. Absence of an $\mathrm{IC}_{50}$ in the normal fibroblast cell line for both $\mathrm{Hy}$ and $\mathrm{Hy}-\mathrm{G} 8$ highlights the cancer cell-oriented cytotoxicity of the agents. The enhanced cytotoxic potential of Hy-G8 in comparison to Hy demonstrated on cancer cells was not observed on 3T3-LI (Fig. 4C, ESI Fig. 4E and $\mathrm{F}_{\dagger}^{\dagger}$ ). Even though both Hy and Hy-G8 produced a maximum cytotoxicity of 18 and $17 \%$ on 3T3-L1 at $80 \mu \mathrm{M}$ at $48 \mathrm{~h}$, lower dosages produced only negligible cytotoxicity; G8 proved to be
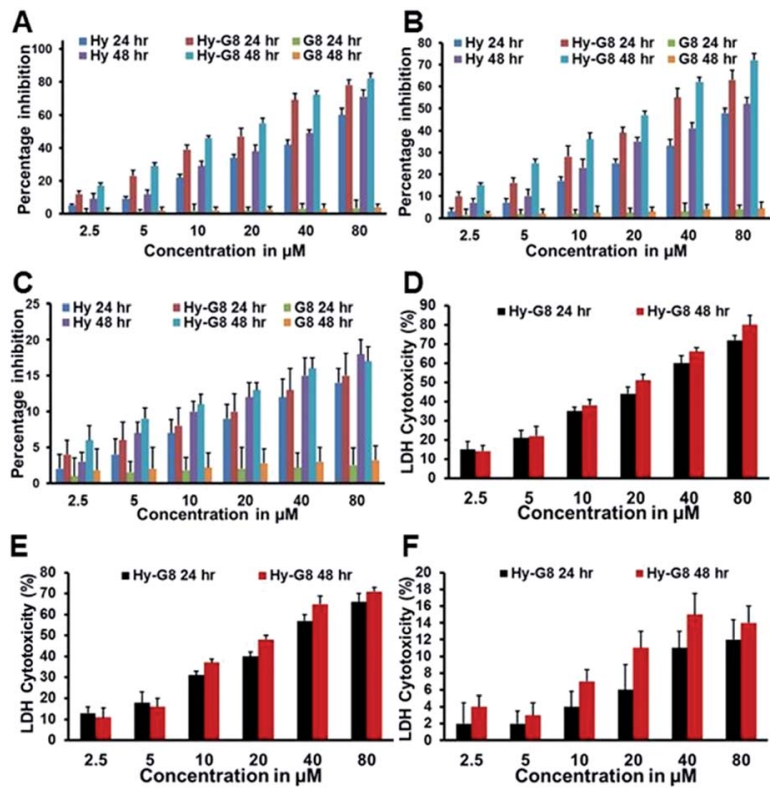

Fig. 4 Assay for cytotoxicity in cancer cells and normal cells treated with $\mathrm{Hy}, \mathrm{Hy}-\mathrm{G} 8$ and $\mathrm{G} 8$ after 24 and 48 h of MTT assay. (A) A375 cells; (B) A549 cells; (C) 3T3-L1 cells. Assessment of the cytotoxicity of HyG8 by LDH assay towards (D) A375 cells; (E) A549 cells and (F) 3T3-L1 cells. 
non-toxic towards non-cancer cells also. The increased cytotoxicity of Hy-G8 than Hy on cancer cells was further tested by quantification of lactate dehydrogenase (LDH) with 24 and $48 \mathrm{~h}$ of compound administration. Hy-G8 exhibited a higher cytotoxicity towards A375 (Fig. 4D) and A549 (Fig. 4E) cells, with marginal cytotoxicity towards 3T3-L1 cells (Fig. 4F). The results obtained from the LDH assay highly correlated with the cytotoxicity evaluation from the MTT assay.

The cytotoxicity of Hy and Hy-G8 evaluated for lung adenocarcinoma, malignant melanoma and fibroblast-like mouse preadipocyte cell line indicates a cancer cell-oriented cytotoxicity profile. Even though Hy alone was found to be a good cytotoxic agent, the G8 coupled construct (Hy-G8) shows superior cytotoxicity towards both the cancer cells, but a similar increase in cytotoxic potential was not found for normal cells. Plasma membrane damage due to cytotoxic agents releases LDH into the cell culture media which could be quantified for determining the percentage of cytotoxicity caused by the agent. The improved cytotoxicity of Hy-G8, which could be attributed to the enhanced water solubility of Hy-G8 in contrast to Hy, was confirmed by MTT and LDH assays.

\subsection{Hy-G8 induced anticancer effects through apoptosis}

To investigate the cell death mechanism induced by Hy-G8 in cancer cells, various apoptotic assays were conducted on A375 and A549 cells after the administration of $20 \mu \mathrm{M}$ of the compound for $24 \mathrm{~h}$. Morphological changes evaluated with phase contrast microscopy revealed a decrease in cell number, which was accompanied by salient morphological features of

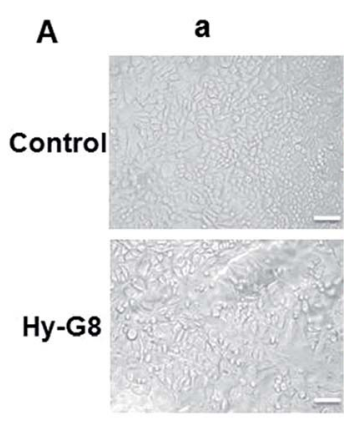

a

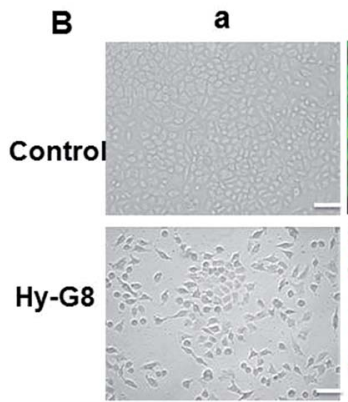

Fig. 5 Morphological evaluation of apoptosis by the $24 \mathrm{~h}$ administration of Hy-G8 $(20 \mu \mathrm{M})$ on (A) A375 and (B) A549 cells; (a) represents phase contrast images, (b) represents acridine orange-ethidium bromide and (c) represents Hoechst staining. The scale bar corresponds to $50 \mu \mathrm{m}$. apoptosis, such as distorted shape, membrane blebbing, and the presence of apoptotic bodies compared to the control group on both A375 (Fig. 5Aa) and A549 (Fig. 5Ba) cells. In comparison with the respective controls, acridine orange-ethidium bromide staining displayed a change in colour from green to yellow/red, which is associated with other apoptotic features such as the presence of apoptotic bodies, damaged cell membrane and nuclear condensation in Hy-G8-treated cells. Significant changes in fluorescence were observed for A375 (Fig. 5Ab) and A549 (Fig. 5Bb) cells. Cells undergoing apoptosis demonstrated nuclear condensation and DNA fragmentation, which was detected by Hoechst 33342 nuclear staining. The percentage of chromatin condensation after Hy-G8 treatment was significantly higher in A375 (Fig. 5Ac) and A549 (Fig. 5Bc) cells compared to the respective controls. The mechanism of cell death induced by Hy-G8 was further confirmed with the TUNEL assay in which propidium iodide was used as counter stain. HyG8-treated cells displayed a green colour indicating TUNEL positivity, but control cells are largely TUNEL negative, indicating the targeted apoptotic induction of the compound on both A375 (Fig. 6A) and A549 cells (Fig. 6B). One of the mechanistic features of apoptotic cell death is the activation of caspases; a class of cysteine proteases and many anticancer drugs was reported to execute apoptosis through a caspase dependent pathway. ${ }^{30}$ Since caspases are the effective mediators of
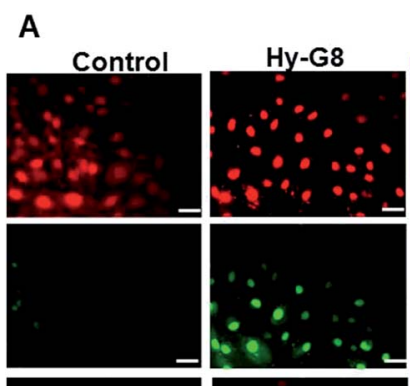

B
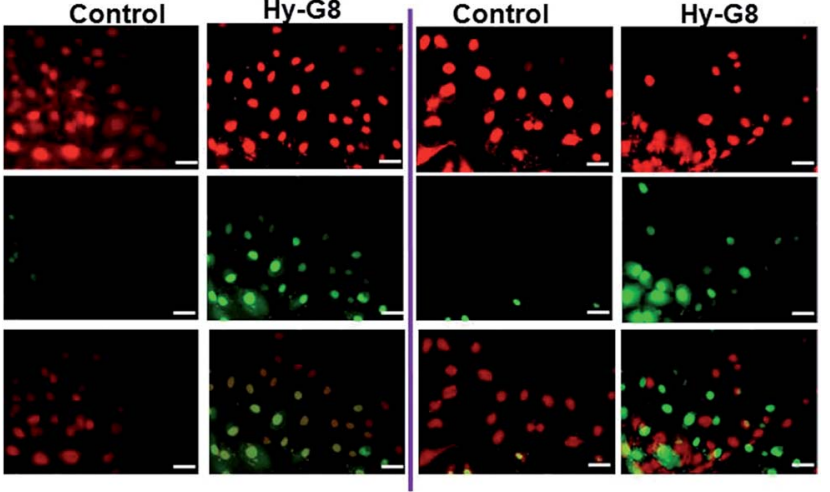

C

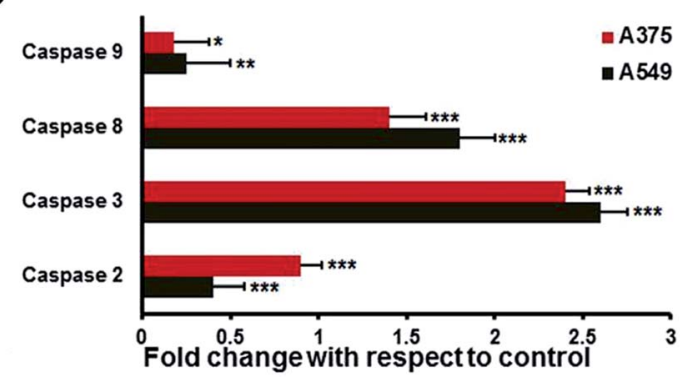

Fig. 6 Morphological evaluation of apoptosis by TUNEL assay after 24 $\mathrm{h}$ administration of $\mathrm{Hy}-\mathrm{G} 8(20 \mu \mathrm{M})$ on (A) A375 and (B) A549 cells. The top panel represents images with $\mathrm{PI}$ filter, the middle panel represents the FITC filter and the bottom panel shows the merged images. The scale bar corresponds to $50 \mu \mathrm{m}$. (C) Caspase activity profiling after $24 \mathrm{~h}$ administration of $\mathrm{Hy}-\mathrm{G} 8(20 \mu \mathrm{M})$ on A375 and A549 cells. Results are expressed as mean \pm SD. 
apoptosis, the expression of caspases 3, 8, 9 and 2 was estimated using fluorimetry to thoroughly substantiate the cell death mechanisms induced by Hy-G8. Both A375 and A549 presented a significant $(P<0.001)$ increase in the expression of caspases 2 , 3 and 8 (Fig. 6C). Caspase 3 was the most over-expressed with 2.4- and 2.6-fold increases within A375 and A549 cells, respectively, in comparison with their controls. The expression pattern of caspase 9 was not that significant in comparison with other caspases in both of the cells.

Apoptosis is the most predominant mode of cell death, and several naturally occurring compounds have shown to induce apoptosis in cancer cell lines. ${ }^{31}$ The presence of irregular bulges in the plasma membrane of the cell due to localized decoupling of the cytoskeleton from the plasma membrane is a hallmark of apoptosis. Although the budding phenomenon of apoptotic cells lasts for only a few minutes, the formation of apoptotic bodies remains visible for a few hours. ${ }^{32}$ The enhanced cytotoxicity of Hy-G8 compared with Hy is found to be effected through caspase-mediated apoptosis.

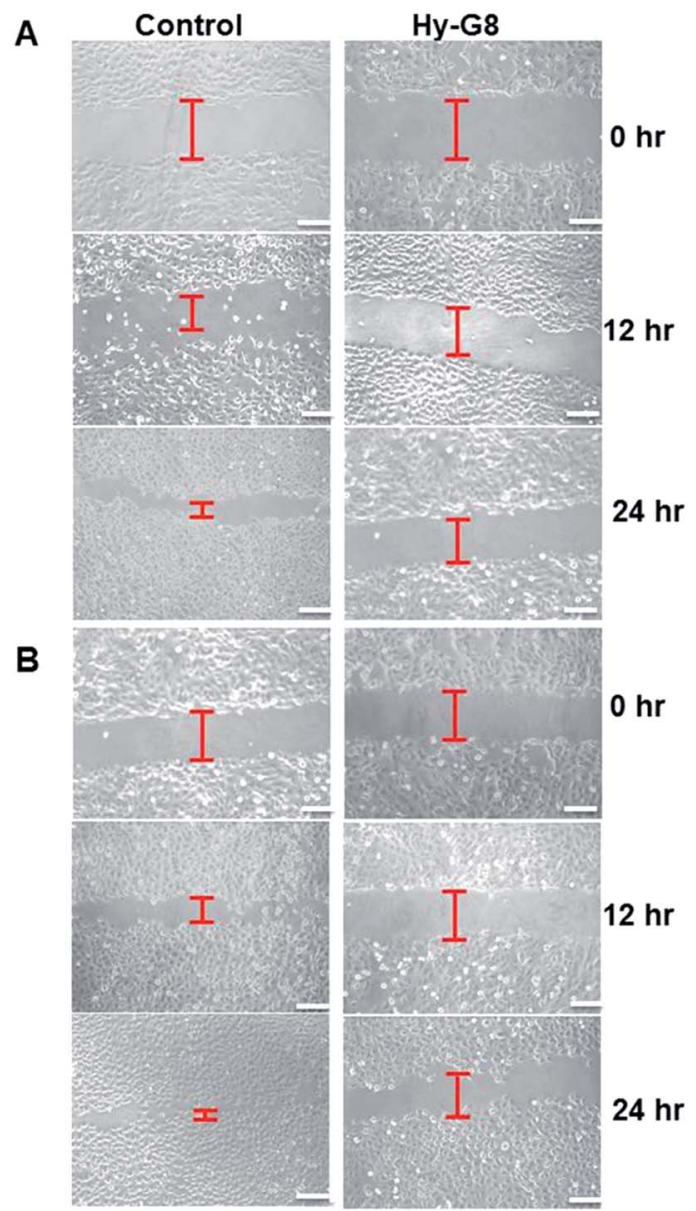

Fig. 7 Representative wound healing images at 0, 12, and 24 hours. Wounds were made with a pipette tip in confluent monolayers on (A) A375 and (B) A549 cells after administration of Hy-G8 $(20 \mu \mathrm{M})$. Red lines indicate the cell-free scratch zone. The scale bar corresponds to $50 \mu \mathrm{m}$.

\subsection{Anti-metastatic potential}

The wound healing assay allows the researcher to study cell migration, cell interactions and metastatic potential of any agent under investigation. The anti-metastatic potential of $\mathrm{Hy}-$ G8 was evaluated for both A375 and A549 cells. It was clearly observed that Hy-G8 could hinder the migration of cells in a time-dependent manner for both A375 (Fig. 7A) and A549 cells (Fig. 7B) whereas the untreated cells attain confluency within 24 h. The cell-free scratch zone of the treated wells are large even after $24 \mathrm{~h}$ but the control wells displayed almost complete closure of the zone even after $12 \mathrm{~h}$ in both of the cell lines. The in vitro scratch assay is an easy, low-cost and well-developed method to measure cell migration. Compared to other methods, the in vitro scratch assay is particularly suitable for studies on the effects of cell-matrix and cell-cell interactions on cell migration, mimicking cell migration during wound healing in vivo, and are compatible with imaging of live cells during migration to monitor intracellular events if desired. ${ }^{33}$ Tumor invasion and metastasis is a multistep process involving cell adhesion, proteolytic degradation and migration through the extra-cellular membrane, angiogenesis and many more. Common chemotherapeutic agents involved in cancer treatment aim at blocking cell cycle progression, inducing cell death and inhibiting tumor migration and thereby metastasis. Several natural compounds $s^{34,35}$ have been reported to exhibit cancer chemoprevention through blocking cell migration.

\section{Conclusions}

Phytochemical investigations on the popularly used medicinal plant Hydnocarpus wightiana Blume (seed) acetone extract decipher its excellent free radical scavenging property with high total phenolic and flavonoid content. The most abundant compound hydnocarpin (Hy), which was isolated, purified and characterised from the extract demonstrates moderate cytotoxic potential towards cancer cells. In an attempt to increase the anticancer potential of Hy, chemical conjugation with a highly efficient, non-toxic cell-penetrating guanidinium-rich poly(propylene imine) dendron (G8) was carried out via EDC coupling. The hybrid molecule (Hy-G8) exhibited excellent cytotoxicity preferentially towards lung adenocarcinoma and malignant melanoma cells mediated through caspasedependent programmed cell death and also demonstrated anti-metastatic potential. The superior anticancer potential of Hy-G8 over hydnocarpin warrants the need for detailed investigations into its molecular mechanistic mode of action both in cell lines and in animal models.

\section{Acknowledgements}

Author KKM wishes to thank Science and Engineering Research Board (SERB), Govt. of India (DST No. SR/S1/OC-67/2012) and Council of Scientific and Industrial Research (CSIR), Govt. of India, network project (NaPHA: CSC-0130), (M2D: CSC-0134), (NanoSHE: BSC-0112) for research funding. Author MMJ wishes to thank Kerala Biotechnology Commission, Govt. of 
Kerala (KBC-KSCSTE) for the Post-Doctoral research fellowship. AcSIR PhD student SMG acknowledges CSIR for research fellowship. AcSIR PhD student JBN acknowledges CSIR network project (M2D) for the research fellowship. The authors also thank CSIR-NIIST for the instrumental facilities and Division of Cancer Research, Regional Cancer Centre (RCC), Thiruvananthapuram.

\section{Notes and references}

1 O. Prakash, A. Kumar, P. Kumar and A. Ajeet, Am. J. Pharmacol. Sci., 2013, 1, 104-115.

2 B. V. Raman, N. V. Krishna, B. N. Rao, M. P. Saradhi and M. V. B. Rao, Int. Res. J. Pharm., 2012, 3, 11-15.

3 (a) A. Bhanot, R. Sharma and M. N. Noolvi, Int. J. Phytomed., 2011, 3, 09-26; (b) A. Saha, S. Mohapatra, P. Kurkute, B. Jana, J. Sarkar, P. Mondal and S. Ghosh, RSC Adv., 2015, 5, 9259692601.

4 M. R. Sahoo, S. P. Dhanabal, A. N. Jadhav, V. Reddy, G. Muguli, U. V. Babu and P. Rangesh, J. Ethnopharmacol., 2014, 154, 17-25.

5 V. Vimberg, M. Kuzma, E. Stodulková, P. Novák, L. Bednárová, M. Šulc and R. Gažák, J. Nat. Prod., 2015, 78, 2095-2103.

6 M. R. Sahoo, S. P. Dhanabal, A. N. Jadhav, V. Reddy, G. Muguli, U. V Babu and P. Rangesh, J. Ethnopharmacol., 2014, 154, 17-25.

7 D. K. Sharma and I. H. Hall, J. Nat. Prod., 1991, 54, 12981302.

8 V. Vimberg, M. Kuzma, E. Stodůlková, P. Novák, L. Bednárová, M. Šulc and R. Gažák, J. Nat. Prod., 2015, 78, 2095-2103.

9 D. K. Sharma and I. H. Hall, J. Nat. Prod., 1991, 54, 12981302.

10 M. R. Sahoo, S. P. Dhanabal, A. N. Jadhav, V. Reddy, G. Muguli, U. V. Babu and P. Rangesh, J. Ethnopharmacol., 2014, 154, 17-25.

11 K. A. L. Pan, Y.-W. Chin, H.-B. Chai, T. N. Ninh and D. D. Soejarto, Bioorg. Med. Chem., 2009, 17, 2219-2224.

12 E. G. Stanzl, B. M. Trantow, J. R. Vargas and P. A. Wender, Acc. Chem. Res., 2013, 46, 2944-2954.

13 J. B. Nair, S. Mohapatra, S. Ghosh and K. K. Maiti, Chem. Commun., 2015, 51, 2403-2406.

14 (a) S. V. Reddy, A. K. Tiwari, U. S. Kumar, R. J. Rao and J. M. Rao, Phys. Ther., 2005, 19, 277-281; (b) S. B. Nimse and D. Pal, R. Soc. Chem., 2015, 5, 27986-28006.
15 P. Molyneux, Songklanakarin J. Sci. Technol., 2004, 26, 211219.

16 I. F. Benzie and J. J. Strain, Anal. Biochem., 1996, 239, 70-76.

17 R. Singh, N. Singh, B. S. Saini and H. S. Rao, Indian J. Pharmacol., 2008, 40, 147-151.

18 F. Liu, V. E. C. Ooi and S. T. Chang, Life Sci., 1997, 60, 763771.

19 L. A. Shaver, S. H. Leung, A. Puderbaugh and S. Angel, J. Chem. Educ., 2011, 88, 492-495.

20 M. S. Stankovi, Kragujev. J. Sci., 2011, 33, 63-72.

21 R. Sahu and J. Saxena, J. Pharmacogn. Phytochem., 2013, 2, 176-179.

22 M. M. Joseph, S. R. Aravind, S. Varghese, S. Mini and T. T. Sreelekha, Colloids Surf., B, 2013, 104, 32-39.

23 M. M. Joseph, S. R. Aravind, S. K. George, K. Raveendran Pillai, S. Mini and T. T. Sreelekha, J. Biomed. Nanotechnol., 2014, 10, 3253-3268.

24 F.-Y. Zhang, Y. Hu, Z.-Y. Que, P. Wang, Y.-H. Liu, Z.-H. Wang and Y.-X. Xue, Int. J. Mol. Sci., 2015, 16, 23823-23848.

25 A. Shiozaki, X. Bai, G. Shen-Tu, S. Moodley, H. Takeshita, S.-Y. Fung, Y. Wang, S. Keshavjee and M. Liu, PLoS One, 2012, 7, e38049.

26 M. N. Alam, N. J. Bristi and M. Rafiquzzaman, Saudi Pharm. J., 2013, 21, 143-152.

27 E. J. Garcia, T. L. Cadorin Oldoni, S. M. de Alencar, A. Reis, A. D. Loguercio and R. H. Miranda Grande, Braz. Dent. J., 2012, 23, 22-27.

28 B. H. A. Meziti, H. Meziti, K. Boudiaf and B. Mustapha, World. Acad. Sci. Eng. Tech., 2012, 64, 24-32.

29 L. Bravo, D. Sources and N. Significance, Nutr. Rev., 1998, 56, 317-333.

30 A. Vaculova, V. Kaminskyy, E. Jalalvand, O. Surova and B. Zhivotovsky, Mol. Cancer, 2010, 9, 87.

31 Y. Dong, C. Y. Kwan, Z. N. Chen and M. M. Yang, Res. Commun. Mol. Pathol. Pharmacol., 1996, 92, 140-148.

32 B. A. Barres, I. K. Hart, H. S. Coles, J. F. Burne, J. T. Voyvodic, W. D. Richardson and M. C. Raff, Cell, 1992, 70, 31-46.

33 C.-C. Liang, A. Y. Park and J.-L. Guan, Nat. Protoc., 2007, 2, 329-333.

34 T. Kuno, T. Tsukamoto, A. Hara and T. Tanaka, J. Biophys. Chem., 2012, 3, 156-173.

35 L. S. Adams, S. Phung, N. Yee, N. P. Seeram, L. Li and S. Chen, Cancer Res., 2010, 70, 3594-3605. 